\title{
Teacher Candidates and the Open Classroom: Concerns for Professional Growth Safety, and Collaboration
}

Excelsior: Leadership in

Teaching and Learning 2020, Vol. 13(1) 27-49

(C) The Author 2020

CC-BY 4.0 International Reprints and permissions: surface.syr.edu/excelsior https://doi.org/10.14305/jn.194

40413.2020.13.1.02

nyacte.org

\section{iD Adam Huck ${ }^{1}$}

\begin{abstract}
Environmental factors, personal experience, and social interactions influence the development of teacher candidates' views of teachers' roles in school and society (Rose, Monda-Amaya, \& Preast, 2018). This is especially true when we consider the unique needs of each generation of teachers. Ecological systems theory and social cognitive theory frame this study as teacher candidates are the product of their personal experiences and social interactions within an education system that must respond to evolving societal needs. This paper presents a descriptive analysis of two sections of a literacy methods course through the study of reflection journals, survey data, and exit interviews. Themes and patterns were identified within teacher candidates' responses (Glesne, 2011). Findings demonstrated that teacher candidates exhibited concerns and fears for not only their professional growth, but also the academic and emotional development of their students. The research occurred in the context of a Professional Development School (PDS) in an urban setting. The first section of the course identified the site's open classroom layout as a physical safety concern due to the rising prevalence of school violence from internal and external sources. The second section identified support structures for teachers and students that demonstrated a concern for emotional safety. This study highlights the need to recognize teacher candidates' unique generational experiences and their desires for safety and collaboration as part of their professional development as educators.
\end{abstract}

\section{Keywords}

open classroom, teacher candidates, ecological systems, social cognitive theory

\footnotetext{
${ }^{1}$ Roberts Wesleyan College

Corresponding Author:

Adam Huck, Roberts Wesleyan College, 2301 Westside Drive, Rochester, NY 14624

Email: huck_adam@roberts.edu
} 
Teacher candidates from Generation $Z$ are entering teacher preparation programs and beginning to accept their first professional positions. This generation, like those before it, have unique experiences and viewpoints that can and will affect their roles as teachers. They "bring their personal beliefs and values about the ethical purpose of teaching and the role of the teacher..." (Cevher-Kalburan, 2014, p. 1). While there are many individual factors that shape each unique teacher candidate, "there are common events and contextual factors that cut across the generation as a whole" (Seemiller \& Grace, 2016, p. 26). One factor that is prevalent across this generation is the exposure to tragedies made readily available through the ubiquitous access to news and information. Specifically, a rise in school shootings and other negative experiences in schools has brought tragedies to the forefront of teacher candidates' individual experiences. Since the collection and analysis of data for this paper, teacher candidates are viewing and experiencing wider societal issues such as increased protests to police violence and the COVID-19 pandemic that is impacting them and their future students.

As teacher candidates create educational experiences for their students, teacher educators must work to identify and respond to the emotional impact of prior experience on the development of teacher candidates. This concern for safety in schools also impacts students' emotional needs. As teacher candidates gain experience in various schools through field experiences, their experience as students shape their views of teachers and teaching. How these lived experiences to reactionary policies (e.g. metal detectors, lockdown drills, surveillance equipment) related to school safety impact teacher candidates' perceptions allows teacher education programs to gain a clearer understanding of student beliefs, fears, and needs. This understanding can subsequently guide continued development of instruction and professional development. This study sought to investigate the influence of teacher candidates' experiences and beliefs as they participate in an urban field experience. Specifically, two research questions were investigated: 1 .) What concerns and fears do teacher candidates reveal through the lens of their belief structure when engaged in field experience in an open classroom model? 2.) How, if at all, does a school's physical structure affect teacher candidates' beliefs/perspectives of teachers and teaching?

\section{Background}

Since Generation $Z$ is currently in teacher preparation programs and beginning to be hired as new teachers, this paper serves to contribute to foundational research being conducted with this generation of teachers. While Iorgulescu (2016) notes disagreement in the research as to the starting point of this generation, this paper will use the birth year 1995 as the starting point. This year is more commonly referenced and places its oldest members as some of the newest teachers in or entering the workforce.

As each new generation of teachers enter the profession, it is useful to investigate the implications of their lived experiences on their beliefs and value structures. These structures impact their perceptions of the role of teachers and enactment of policy in the classroom. The interplay of environmental and public policy factors contribute to teacher candidates' concerns for self and their students. For example, environmental factors, such as mass shootings in schools and universities, have triggered states and districts across the country to implement reactive policies designed to protect students' physical safety. These policies have often led to physical changes in the school building, such as redesigned layouts or surveillance equipment (Schroeder, 2016), with arguable effectiveness. Subsequently, students at all levels internalize messages related to safety and security based on the physical space they occupy in the school. Students develop a view that a foundational function of the school is to prevent physical harm 
from coming to students. These students further their education as teacher candidates holding belief structures related to the school's physical space. These structures influence entrance into the profession through perceptions of the individual school and the education system. As Pace (2011) noted, "Teachers are not passive victims of school policy; they continue to make important decisions as they interpret policy and create educational experiences for their students" (p. 34).

Central to this study are beliefs and experiences, so these terms must first be defined. In referencing the work of Domović and Vizek Vidović (2013), Šimić Šašić, Šimunić, Ivković, and Ključe (2018) defined teacher beliefs as "a set of conceptual concepts that include general knowledge of phenomena, people and events related to their professional context" (p. 208). With this definition in mind, this paper considers teacher candidates' beliefs as a result of their experience with phenomena, people, and events in the context of the school and classroom. Ingman and McConnell Moroye (2019) "define the student experience as the intentionally organized lived encounters that students undergo during the school day" (p. 348). Due to changes in such areas as technology and policy, each generation's experiences are different in this professional context.

One reason to consider teacher candidates' belief structures is to ascertain their rationale for entering the profession. This is helpful for considering efforts to attract and retain teachers as well as teachers' reasons for remaining in the profession. Redding and Henry (2019) note that teacher turnover is on the rise, especially in segregated schools with high concentrations of students living in poverty. This turnover is not only increasing at the end of the school year, but also during the year thus causing significant disruptions to learning and relationships. The authors noted that this disruption extends beyond the classroom to impact administration and other classrooms. As a result, it is critical to attend to the preparation of teachers and their affective needs to prevent disruptions to schools and careers. Moreover, teachers hold a low status in the public view (Johnson \& Birkeland, 2003), so it is necessary to continue to investigate the motives and perceptions of those entering the profession.

The use of reflective journaling is one way to determine teacher candidates' beliefs and the role of past experiences on the development of those beliefs. This practice allows teacher candidates to write about their experiences and share thoughts and concerns that might not be verbalized. While our experiences help to form our beliefs, they also create feelings such as fear or concern. In the context of this study, these feelings are defined as "perceived problems or issues that are often the focus of thought and action" (Miksza \& Berg, 2013, p. 45). To support the identification and expression of these feelings, reflective comments in journal entries were utilized in this study. Moreover, they were used to support a transition of teacher candidates viewing themselves as teachers, rather than as students, as they reflect on their experiences (Garza, Werner, \& Wendler, 2016).

As teacher candidates spend more time in the field setting, they are more adept at exploring their teacher identity and emerging sense of self (Garza et al., 2016). Haddix (2015) argued that teacher educators must work "toward a process for beginning teachers' critical interrogation of their own social locations and the ways in which they engage with and honor students' lives and histories" (p. 70). Development of teacher candidates' identity involves the "shaping and reshaping of one's values and beliefs about teaching..." (Garza et al., 2016, p. 28) through engagement with students and their communities (Haddix). In this sense, identity is an ongoing and relational process (Oruç, 2013). Moreover, "it is innate and the only source of change is experience" (p. 208). The maturation of this identity is the result of interactions with not only teachers and students, but also education systems as a student and teacher candidate (Sexton, 2008). Thus, this study focuses on the situational experiences and interaction with people and systems as causal factors to the development of belief structures. 


\section{Theoretical Framework}

Environmental factors, personal experience, and social interactions can potentially influence the development of students' perceptions (Rose, Monda-Amaya, \& Preast, 2018). Varied personal experiences are used to construct different realities and perceptions across many issues (Williams $\&$ Corvo, 2005). The ecological systems theory (see Figure 1) can be pictured as a nested structure, much like the Russian dolls nested inside one another (Bronfenbrenner, 1979). On the inside is the immediate setting for the developing individual. This includes the classroom and home. The next stage begins to examine the interactions between and among those most basic settings. Bronfenbrenner used the example of a child learning to read to explain this second stage. A child's reading progression depends on the interconnections of the school and home. At the third level, the "person's development is profoundly affected by events occurring in settings in which the person is not even present" ( $p 3$ ). For example, parental employment influences students' development in many areas. The fourth level considers the overall systems of the culture and subcultures through the interactions of the other three levels. The interaction of these various societal and cultural factors affects child and adolescent development as well as their beliefs and views.

Figure 1

Nested Model of Ecological Systems Originally Proposed by Bronfenbrenner (Neal \& Neal, 2013, p. 725)

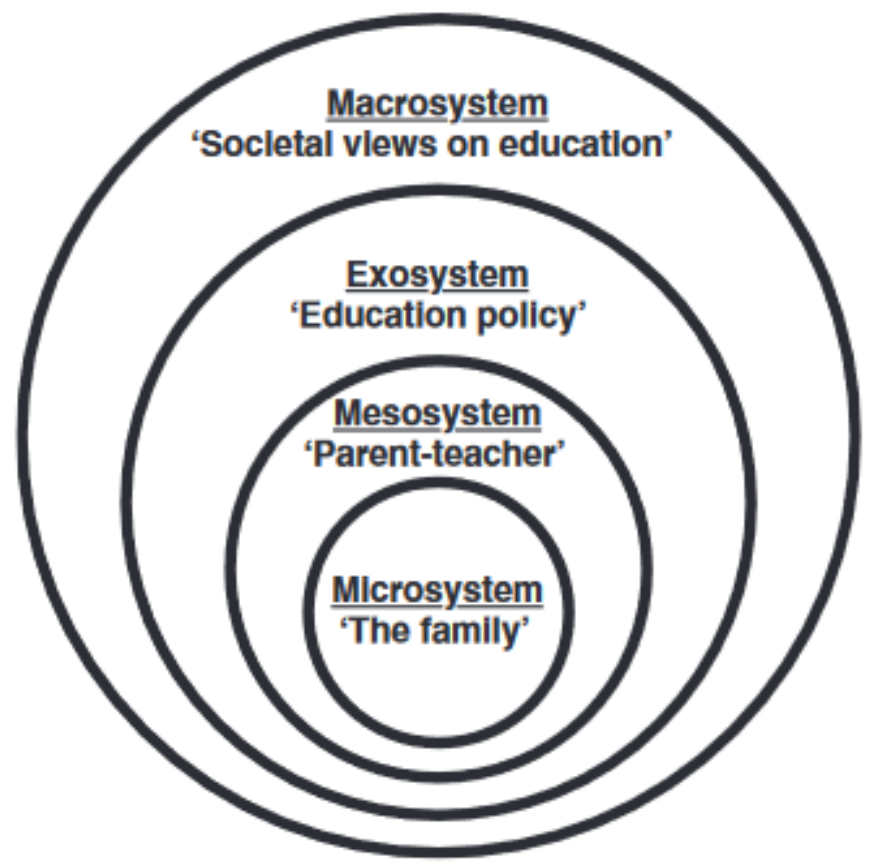

As teacher education programs prepare future teachers to make decisions on their own, a second consideration for this study was the human agency perspective of social cognitive theory. In this sense, people "are not simply onlookers of their behavior. They are contributors to their life circumstances, not just products of them" (Bandura, 2006, p. 164). The first element of human agency is its intentionality. Pursuits are not simply goals, but specific plans and strategies that must consider diverse interests and 
efforts of others. A second property is forethought, in which individuals behave purposefully in consideration of goals and anticipated outcomes. Third, human agency is self-reactive in that it is not only intentional in planning, but able to select and change courses through execution. Finally, selfreflection is evident as humans examine and evaluate efficacy, thoughts, pursuits, and actions. To Bandura, "the metacognitive capability to reflect upon oneself and the adequacy of one's thoughts and actions is the most distinctly human core property of agency" (p. 165). In this sense, the role of selfreflection on experiences and actions is at the core of teacher development.

Consideration of the above theoretical underpinnings frames this study. In one sense, teacher candidates are the product of personal experiences and social interaction within an education system that intends to develop policies to promote student safety. However, as these teacher candidates transition from student to professional, these experiences contribute to perceptions that influence not only their emotional needs, but also their agency as teachers. In regards to the first research question, the utilization of self-reflection allows for the identification and analysis of experiences that contribute to teaching beliefs and agency in the classroom. Specifically, when gathering and analyzing research data, the absence of prior experience in an open classroom creates a need for teacher candidates to consider intentionality in their evaluation of self and others. Teacher candidates' interwoven experiences in the microsystem, mesosystem, exosystem, and macrosystem (Bronfenbrenner, 1979) frames the second research question and its concern for belief structures that have developed over time. Research methods considered the role of self-reflection in identifying the role of prior experience and formation of belief structures. Through analysis of reflection documents, findings identify thoughts behind teacher candidates' beliefs and actions. Moreover, this provided an opportunity to discuss the ecological systems that influenced their developing belief structures.

\section{Literature Review}

Research by Fuller in the 1970's (as cited in Alpan et al., 2014), identified concerns related to self, task, and impact in teacher candidates. In order to continuously improve teacher education programs, Alpan and colleagues recommended the identification of concerns in new teachers to bolster the quality of teacher education programs. In this regard, this paper seeks to identify unique concerns related current teacher candidates.

\section{Open Classrooms}

The open classroom setting of this study presented a unique experience for the teacher candidates. Drummond (2017) traced the origin of the open classroom to the 1960's and 1970's as new school designs sought more openness. Like many changes in education, this design was an approach to beliefs that American students were falling behind. The hope was for more creativity in instruction through individualized means that focused on student interests.

The open classroom concept presents a model that considers space in functionality. This concept merges the influences of "architecture and education that challenges conventional means of control and organisation of school space" (Deed \& Lesko, 2015, p. 218). In terms of architectural design, this model creates physical space and a sense of openness. When applied to education, this concept creates flexibility as well as opportunities for student and teacher choice. This choice allows for more emphasis 
on individual and small group teaching. Moreover, this openness encourages community building within the classroom and school (Gislason, 2007).

Due to the unconventional physical layout, this openness can challenge student and teacher activity. It may disturb instructional practices to allow for inclusion and flexibility (Deed \& Lesko, 2015). For teachers, this openness may bring a sense of vulnerability, but if it is embraced, it can become a form of activism (Schwartz, 2014). Teachers can highlight innovative practices and contribute to policy decisions in a positive format. Moreover, this model creates opportunities for collaboration between teachers, who may be the sole adult in the classroom (Drummond, 2017). Flexibility in instructional practices allows for student differentiation across specialties and grade levels. The open classroom allows students easier access to teachers for instruction, remediation, and concept development.

Like many education initiatives, this movement quickly faded. Drummond (2017) noted a return to closed classroom layouts arose by the late 1970's. Three contributive issues precipitated this decline. First, its unfamiliarity is a challenge to teachers who instinctively create borders and partitions with furniture, bulletin boards, and other large items (Drummond, 2017). Second, and most noticeably, is the increased number and volume of sounds that penetrate these learning spaces. Drummond quotes teachers that articulate this openness as increased "noise." Teachers must maintain a distinct mindset in order to teach in this space. For many, this school layout runs counter to their experiences as a student and teacher candidate and takes considerable adjustment in instructional design and methods. Finally, education policies continue to swing from progressive to conservative and back again. Thus, a model once considered progressive gave way to more conservative models and designs.

Conservative policies and ideologies oppose the openness of these classrooms and call for more tightly controlled administrative policies. This mindset believes that tight control of curriculum, teaching, and students will restore the discipline and competition of a romanticized past (Apple, 2013). Therefore, as policy makers continue to seek accountability and curricular control, the remaining open classrooms become ideological anomalies that challenge teacher candidates and teacher educators alike. Policies intent on control of schooling and classrooms are also at the heart of logistical concerns for maintaining school safety.

\section{School Safety}

Every generation has experienced and responded to disasters and tragedies (Seemiller \& Grace, 2016). However, this generation is different because access to multimodal information presents evidence of terrorism that helps bring these events "closer to home" (p. 36). While school shootings and other violence in schools have occurred for decades, recent trends in public opinion demonstrate rising concerns for student safety (Phi Delta Kappa International, 2018). Following the shooting at Marjory Stoneman Douglas High School in Parkland, Florida, the Trump administration convened a commission "designed to both research and recommend solutions to advance the safety of our schools" (Federal Commission on School Safety, 2018, p. i). However, this commission lacked power to enact policy and recognized that the shooting in Parkland is not likely to be the last. Tragically, it was not. According to data from the most recent Youth Risk Behavior Survey, the percent of high school students that do not attend school due to safety concerns has risen since 1993 (Centers for Disease Control and Prevention, 2017). The safety measures and precautions currently in place are not allaying students' concerns for their safety. 
Similar results were noted in the views of parents. In their most recent poll, the Phi Delta Kappan (2018) found about $27 \%$ of parents expressed confidence in the ability of their child's schools to deter an attack. Additionally, parents are increasingly fearful of their child's safety in school. This particular concern has risen sharply in recent years. Underscoring the influence of many factors on teacher candidates' perceptions was the finding that parents with lower incomes (less than $\$ 50,000$ ) were twice as likely to express this fear as compared to those with higher income levels (greater than $\$ 100,000$ ). Additionally, nonwhite parents in urban areas expressed this fear at over $40 \%$. It is important to note that school climate and fears vary among distinct demographic groups within the school (Brand et al., 2003). Moreover, enduring societal bias and discrimination impact parents' and students' views of access and opportunity within the school (Hill et al., 2018). While outside factors impact the views of subpopulations, this is complicated with the variance in climate within the school as well as systemic biases impacting parental concerns regarding three types of safety: academic, emotional, and physical.

While the Federal Commission on School Safety lists notable school shootings dating back as far as 1979 , the increasing fears noted by the Phi Delta Kappan survey suggest a change in public perceptions of these incidents and the reactive policies implemented by public policy initiatives. Traditional and social media coverage may further complicate the analysis of these sentiments (White \& Beal, 1999) along with the narratives and divisiveness of potential solutions. One incident, such as Columbine, or a combination of incidents repeated in the media can stoke fear, despite individual personal experience (Williams \& Corvo, 2005). This fear then contributes to students' needs for emotional support.

Since teachers are with their students for the majority of the school day, they are most directly responsible for the physical and emotional security of their students. As noted above, students and parents express concerns over school safety, so we must seek to deepen our understanding of teacher candidates' fears and concerns (Williams \& Corvo, 2005). Once we have this understanding, teacher preparation and new teacher mentoring programs can develop supports to minimize new teacher fears and be better prepared to ensure student safety. In its report to the President, the Federal Commission on School Safety noted, "teachers are often best positioned to identify and address disorderly conduct at school" (p. 67). Therefore, it is critical that we understand the mindsets of teacher candidates, address their fears, and prepare them for the myriad responsibilities of the profession.

With the concern for school and student safety, district and building level administrators have attempted to respond to the fears of the community. According to the National Center for Education Statistics (NCES), school safety measures may take two forms (National Center for Education Statistics, 2018). These practices include those intended to manage access to the building and those intended to manage human behavior within the school. In the last twenty years, the NCES has noted increases in the presence of controlled access during school hours, presence of security cameras, required presence of badges or identification for staff, dress code, random dog sniffs for drugs, student uniforms, and required presence of badges or identification for students. Administrators and policy makers enact these policies with the intention to keep schools safe and are regularly visible to students. However, over time, these actions become commonplace for students who expect them in all school environments.

Of particular interest to this study is the safety and security measures enacted at large, urban schools with a high percentage of students receiving free or reduced lunch. According to NCES, in each of these identifiers, the listed precautions were more prevalent. This is noteworthy for two reasons. First, current students in these environments receive the message that heightened security measures are the norm and are necessary for student safety. Second, teacher candidates that are unaccustomed to the increased 
presence or these precautionary measures may view the school, and thus the students, negatively. Two decades ago, Bowman (2001) noted that responses to school violence have started in urban centers and moved to suburban districts. So, teacher candidates from suburban schools must adjust and adapt to violence prevention policies that are likely to be more prevalent in the urban district of their field experience. While school violence has occurred at schools of varying types, the inequitable policies of prevention may be attributed to the perception of urban schools and culture as aggressive (Smith, 2011). Moreover, school surveillance policies are largely advocated by a white and middle class population that "privileges and discriminates along racial and class lines" (Schroeder, 2016). Schroeder argued that when students experience inequitable surveillance practices in schools, problems result in financial burdens, psychological trauma, and a pervasive culture of fear. As a result, impacted students are at an elevated risk when safety measures are applied inequitably. This inequitable distribution thus creates variances in teacher candidates' belief structures.

\section{Perceptions and Beliefs}

Luft (2009) defines beliefs as "personal constructs that are important to a teacher's practice - they guide instructional decisions, influence classroom management, and impact the representation of the content" (p. 2358). Moreover, these beliefs are true to the individual and based on personal experience and feelings. This is different from knowledge, which is more evidential and group oriented. As teacher candidates enter their methods courses in their teacher preparation programs, many will align their beliefs and experiences with pedagogies (Miller, 2007). They may not be fully aware of this act, but their belief structure influences their teaching philosophy and actions in the school. Perception is also important when considering response to behaviors, such as aggression (Rose et al., 2018). Teacher candidates' perceptions regarding specific issues and behaviors shape their responses in the classroom.

As teacher candidates gain new experiences, their beliefs and perceptions alter, or even clash, with new learning. One example of this adaptation is in the focus of concern. Williams and Corvo (2005) found that teacher candidates tended to focus on themselves when expressing concerns of violence, while in-service teachers tended to focus on harm coming to students. Therefore, perceptions are modified as maturity and experience develop. In this way, Bronfenbrenner's (1979) nested structure of ecological systems theory is evident in the changing motivational setting. A further complication is in the enactment of beliefs through teacher action. "The connection between espoused and enacted beliefs is not straightforward" (Barrett, 2013, p. 16). Experience may play a role in the development of perceptions and beliefs, but other factors may be involved.

While instruction and professional development seek to develop new teachers' knowledge and skills, some prior belief structures clash with new experiences. For example, Barrett (2015) found that teachers that grew up in strongly religious families and communities might find it difficult to work in environments that do not espouse their beliefs. These deeply held values influence their teaching practice in subtle and not so subtle ways, such as instructional questioning and room decorations. Barrett studied a teacher that struggled with ethical decisions related to her Mennonite background and the more contemporary environment of her school setting. Barrett posited that teachers and students alike bring their experiences with them when they enter the classroom and these experiences are rooted in their perceptions and decision-making. Accordingly, "teachers' enacted beliefs will depend on espoused beliefs related to both their work and personal lives..." (p. 5). For example, the teacher in Barrett's study desired to provide deep connections between religion and the curriculum, but struggled 
to implement the activities necessary to do so. Her Mennonite background instilled an avoidance of conflict, something necessary and beneficial to deepen student understanding. In this way, she entered and exited her teacher education program with a continuum of prior knowledge that dictated her instructional practice (Rose et al., 2018).

Teacher candidates' motivation and commitment are impacted by their personal and environmental expectations (Chesnut \& Cullen, 2014). While teacher candidates do not necessarily work in the school every day, the favorability of their experiences affects their satisfaction, self-efficacy, and perceptions of the profession. With concern regarding the levels of inflexibility and permanence of teacher candidates' perceptions, it is important to understand value structures of teacher candidates to improve teacher preparation practices (Fajet, Bello, Leftwich, Mesler, \& Shaver, 2005). These structures are largely influenced by their experiences and can help or hinder developmental processes. By investigating teacher candidates' experiences and perceptions before and after placement in a field setting, teacher preparation programs can design experiences with authenticity (Fajet et al., 2005).

\section{Method}

A theory-led analytic procedure was utilized and methods were grounded in pre-established theories (Hayes, 1997). Themes of analysis were established based on the previous course, established theories, and a review of literature. Then, data were collected and analyzed based on themes of open classroom and school safety. Words and phrases from data were coded and analyzed for common attributes and a narrowing of the general themes.

\section{Study Background}

This study occurred in a Professional Development School (PDS) setting located in an urban school district through a collaboration with the local college. Teacher candidates registered for a literacy methods course as part of their teacher preparation program. This course, typically taken in the junior year, begins with on campus meetings for the first three weeks of the semester and then placement in classrooms at an elementary school for the remainder of the semester. During their placement, teacher candidates are at the elementary school for four hours on Mondays and Wednesdays.

As part of the PDS model, the researcher collaborated with classroom teachers and other school faculty and staff to promote effective and responsive classroom practices. The researcher met with the school liaison to collaborate on the strengths and needs of the school partnership and teacher candidates. Classroom teachers supervised the teacher candidates and were able to communicate with the researcher on site. The researcher communicated in person and electronically with classroom teachers to monitor the teacher candidates' progress. The teacher candidates met with both their mentor classroom teacher and the researcher for formal and informal debriefing sessions to discuss their progress in implementing not only district created curriculum, but also research based practices they learned in their teacher preparation program. With the researcher on-site for all sessions, there were more frequent opportunities to collaborate with school personnel in the progress of the teacher candidates. With the researcher observing all teacher candidates for every session, continuous opportunities were available for reflective practices on classroom instruction.

The elementary school featured in this research has an open classroom layout that is unique to the district and surrounding areas. Prior to placement in the classroom, teacher candidates participate in an 
orientation visit that acclimates them to the school, curriculum, students, overall layout, and various other aspects to prepare them for their extended time at the school. Once placed in a classroom, teacher candidates complete multiple assignments, including weekly reflections on various topics related to their experiences in the classroom and school. The first journal topic requires teacher candidates to reflect on their orientation and first week in the classroom:

Journal Entry \#1: (A) What did you learn from the Orientation (about the administration, teachers, children, families, school climate, surrounding community, curriculum, literacy program)? Please give specific examplesfrom the orientation session. What questions remain for you? (B) What are your impressions of your classroom, students, and cooperating teacher? How will you use the resources available for your own assignments and for your work with children? (C) As you toured the school, what stood out for you?

Teacher candidates expressed excitement and anxiety as they prepared to work in this new environment, and these responses were to be expected. However, during the orientation session, one teacher candidate in the first cohort group questioned the school liaison on school safety procedures and drills as they pertained to the open layout of the classrooms and school. This concern for student safety appeared to carry over into other teacher candidates' written responses for their first journal entry as described above. Demonstrating the possible power of suggestion, fourteen out of fifteen teacher candidates discussed the unique layout of the open classroom design with concern for student safety. The teacher candidate that did not mention this concern was absent from the orientation, and thus did not hear the questioning from her peer. Within their first reflection journal entries, this group of teacher candidates expressed varying levels of concern for student and staff safety in the event of an outside threat of violence, such as an active shooter. Specifically, how could teachers protect students in the event of a lockdown without a fourth classroom wall to shield and hide students? In the reflections, teacher candidates expressed a range of emotions from uncertainty and curiosity to strong sentiments of alarm. This expressed concern became the impetus for this investigation into the influence of teacher candidates' beliefs on their development as new teachers.

The following semester, Spring 2019, an investigation was conducted to focus intentionally on the responses to this first journal entry and the emotional needs expressed and identified by teacher candidates. An initial survey was given to the teacher candidates (Appendix A) to gather background information prior to visiting the site. Questions pertained to the course as well as this study. The course then followed the same structure as the Fall cohort and data was collected from this journal entry along with observational and interview data.

\section{Description of Participants}

Participants registered for this course with the researcher as part of their standard course registration process. Thus, this study utilized a convenience sampling. Eleven teacher candidates enrolled in the course for the Spring 2019 semester. This represented a different set of students from the Fall 2018 semester outlined in the study background. As described above, teacher candidates typically register for this course as juniors and this group included nine juniors, one sophomore, and one senior. 


\section{Description of Sites}

As a field experience-based methods course, there were two main sites for course meetings. The first was on the campus of a public college in an urban area in the northeastern United States. According to Data USA, approximately $50 \%$ of the college's student body is identified as white. The next largest racial subgroups are African American (29\%) and Hispanic (12\%). According to the college's website, $56 \%$ of undergraduate students are female and $44 \%$ are male.

A second site, and the primary focus of this study, was a public elementary school in an urban district approximately three miles from the campus site offering grades Pre-Kindergarten-Grade 4 . The building was constructed in the mid-1990's with open classrooms, unusual when considering the peak decade for this construction model was in the 1960's. For every three open classrooms, a common area is available for small group instruction, learning centers, and imaginative play. According to state education data, students at this school are 72.5\% African American, 9.9\% Hispanic, 9.1\% Asian or Pacific Islander, and 5\% White. In the most recent state assessments, $20 \%$ of students at grades 3 and 4 are at the proficient level in English Language Arts, down $2 \%$ from the previous school year. This is similar to district results, but below the state average of $45 \%$. In Math, $17 \%$ of students are at the proficient level, an increase of $4 \%$ from the previous year. This is below the district average of $21 \%$ and state average of $45 \%$.

\section{Data Collection}

Document analysis was utilized for data collection. Documents gathered included an initial course survey and reflective journal responses. The course survey (Appendix A) gathered background knowledge of the teacher candidates in areas related to the course, including their experiences with school safety and open classrooms $(3-8,10)$. Other questions $(1,2,9)$ were not directly related to the study and were used to gather information about the students that would support development in the course. Teacher candidates responded to a journal prompt to describe their initial reactions to the site following a tour and one week as classroom participant observers.

In order to triangulate findings, discussion data through the use of an exit interview (Appendix B) at the conclusion of the course also provided comparative information as to teacher candidates' views of the course and experience. Conversations throughout the course as well as additional journal reflections served to monitor teacher candidates' views and concerns.

\section{Data Analysis}

The use of ecological systems theory and social cognitive theory framed data analysis. Utilizing the ecological systems theory, the focal individuals were the teacher candidates as they interacted with students, faculty, and staff. The teacher candidates had direct experiences and social interactions within the PDS site as a microsystem (Neal \& Neal, 2013). However, there was a recognition that the role of mesosystems, exosystems, and macrosystems (see Figure 1) beyond the school impacted, and continue to impact, the teacher candidates' beliefs and value structures. The ecological systems theory framed data analysis through the identification of codes that represented the role of the classroom on the development of students as well as teacher candidates. 
For the purposes of this study, descriptive analysis of teacher candidates' responses to the initial journal prompt were coded and analyzed for themes and patterns (Glesne, 2011). Emergent codes were created through repeated readings of the journal entries. When reading the entries, three broad themes emerged to bring a more narrow focus to the pre-established themes: open classroom, student support, and teacher support. Following this step, repetition of words and phrases were identified to recognize patterns across responses and provide further description within each theme. The following are examples for each theme. While the term open classroom was repeated, it was linked to other descriptors as "open air classroom," "one big classroom," and "open concept." For support to students, a common word across responses was "breakfast" in recognition that the school provided a free breakfast to all students. The word "nice" was also repeated across most responses to describe cooperating teachers and school staff. When considering the theoretical lens of the study, teacher candidates recognized the impact of students' environment on their school experience as well as the benefits to themselves through social interaction within the classroom and school.

As described above, there are four aspects to social cognitive theory outlined by Bandura (2006): intentionality, forethought, self-reactiveness, and self-reflectiveness. These core features allow people to exercise agency in response to environmental experiences. "The metacognitive capability to reflect upon oneself and the adequacy of one's thoughts and actions is another distinctly core human feature of agency" (Bandura, 2001, n.p.). Data analysis focused on the core feature of self-reflectiveness as teacher candidates reflected on their beliefs and motivations. The mechanism to self-reflect is central to the development of teacher candidates' self-efficacy as they enter new environments to develop their instructional practices. By utilizing this framework, codes were identified that reflected the impact of teacher candidates' experience on their views of the roles of schools and teachers.

The concerns and fears of teacher candidates as well as the role of the physical structure of the school guided data analysis through the theory-led analytic procedures. Data analysis was a staged process that involved multiple readings (LeCompte \& Preissle, 1993a). First, the researcher read and scored all reflection journal responses using a rubric (Appendix $C$ ) following the first week of the placement. This allowed broad patterns to emerge across entries. Then, rereading of journal entries occurred at the end of the course to begin analytic identification of codes and relationships among categories. The researcher analyzed from whole to part (Erickson, 2004) through subsequent readings to identify meaningful codes related to the beliefs and concerns of teacher candidates. Cyclical data analysis occurred throughout the study in order to narrow codes and seek meaning through participants' responses.

\section{Findings}

With the informal data gathered from the Fall cohort, there was an expectation that school safety may be a focus of teacher candidates at this point in their educational trajectory. Therefore, this study investigated the concerns unique to current teacher candidates through the lens of ecological systems. An additional focus was the impact of physical space on teacher candidates' emotional needs. While the concern for physical safety did not specifically materialize for the second cohort, concerns for emotional safety and support were largely present. Through data collection procedures described above, three themes emerged: teacher candidates' concern for their own emotional wellbeing, the availability of support structures for students, and the impact of the physical layout on student and teacher growth. In 
seeking reliability, attention was given to the coding system, sources of data, and member checking through the exit interviews (Morse, 2015).

\section{Concern for Self}

Out of the eleven journal responses, ten identified structures in place at the school that would benefit their transition to the classroom as a teacher. For example, six responses described their cooperating teacher as "nice" and others used similar descriptors of support such as "helpful." One teacher candidate valued the opportunity to immediately participate in the classroom. She stated that her mentor teacher "was very nice and gave us ways to get involved with the students and their work." Additionally, these ten respondents highlighted the availability of their mentor teacher to make them comfortable in their transition to this classroom.

As part of the PDS relationship, faculty, staff, and administration were engaged with the teacher candidates in a variety of ways. Some were invited to speak to the teacher candidates about their roles in the school, students' needs, and other relevant topics. The teacher candidates viewed these speakers as "very motivating" as they "emphasized the importance of planning and communication." These supportive attributes extended beyond the classroom teacher and included the entire staff. One teacher candidate noted the simple acts of smiling and saying "hello" were meaningful in helping them feel welcomed and supported in the school. Moreover, these social interactions with faculty and staff provided an opportunity for these teacher candidates to "build a bond" with the students and teachers in the school, despite their limited presence in the school.

It should be noted that one teacher candidate did not mention or discuss the social interactions or potential emotional support in the school. Instead, this teacher candidate wrote a narrative describing the events of the week and the features of the school. A comparison of this journal entry to the responses of the initial survey noted that this teacher candidate was returning to the college program as a nontraditional student after a long break due to the birth of her child. As a result, she was approximately ten years older than the rest of the teacher candidates in the course. Thus, she brought different experiences and views to the course as compared to the other teacher candidates in the course.

\section{Concern for Students}

As the teacher candidates viewed the school from an outsider's perspective, they also noted the many supports available to students at the school. Several teacher candidates noted the value of the school's health clinic as a means to provide much needed medical service to students. "The idea of the health center was very impressive to me." Specifically, the ability of the health clinic to prescribe medications for students was valued by teacher candidates as a means to keep students in school.

When considering teacher candidates' responses to the journal prompt described above, teacher candidates noted supports present for students. For example, seven respondents discussed the school's free breakfast program as a benefit to all students, especially those living in poverty. One teacher candidate noticed a food shelf that was available to students with noodles, soup, cereal, and other nonperishable items. "Knowing that a lot of the students live in poverty, this source of free food can help the students get through some rough times." Through the orientation experience, teacher candidates learned that a majority of students live below the poverty line and struggle to get food at home. "One 
way they try to combat hunger in their students is by providing every student with breakfast and lunch while they are in school. In my opinion, this is amazing."

Classroom and building structures were also noted to support students' sense of pride in their culture. "I love how the school embraces their student's differences and cultures." Teacher candidates noted evidence that the school embraced students' cultures through the hanging of flags and student work. This display was considered "vivid" by one teacher candidate. Moreover, "the cases in that hall had letters written by (students) describing themselves and their cultures and religions and what languages they spoke." Teacher candidates noted the consideration of food served in the cafeteria. "They do not serve pork in the cafeteria, and their vegetarian students go first in line." A teacher candidate appreciated the authenticity of displays for Black History Month as well as the displays celebrating African Americans posted on the school's walls throughout the year. In recognizing all elements of the school, one teacher candidate stated, "I admire the way they embrace all of their students' cultures and differences and showcased them proudly within their main hall."

In addition to the physical supports, teacher candidates identified practices to support students' emotional development. The daily greetings and circle conversations in each of their placement classrooms strengthened bonds among students as well as between students and teachers. Common practices across classrooms were the morning greeting and circle time. The open layout allowed teachers to easily greet all their students in the morning in an open atmosphere. For example,"most of the students gave her (classroom teacher) a hug so I know that she's built a positive bond between her and her students. This greeting also helps them prepare emotionally to have students start off their day on a good foot." The circle time allowed students to share their current feelings along with any reasons for their feelings. This marked "a positive way to start the day." Finally, the connection to the students was viewed as a benefit to further growth as an educator. One teacher candidate concluded her entry by stating that she was excited to "build a bond with the students and teachers in order to further my teaching experience." This was noteworthy in the recognition that a focus on developing relationships with students could improve her teaching.

\section{Physical Layout}

According to the initial course survey (Appendix A), students' initial experiences and views of open classrooms were mixed. Of those surveyed, five students demonstrated some prior knowledge or opinion of the open classroom model. Within this group, four of the five articulated at least a modicum of positivity in their initial views of the model. One student noted the potential for increased "efficiency" and "students can meet more people." Similarly, another student noted that the open classroom model, "allows students to be more engaged with each other and move freely around the room." One comment, though, simply stated, "I like the idea of an open classroom" without further explanation. A fourth student stated, "they [open classrooms] are encouraging to an extent." So, while aware of open classrooms and their potential opportunities, the qualifier at the end signaled hesitation or potential cause for concern. Finally, the fifth student was opposed to open classrooms, but was willing to learn. She simply stated: "not a fan but willing to adapt."

While question 8 (Appendix $A$ ) required students to express their current views and beliefs about education, question 10 required students to draw their ideal classroom. This task was included to determine the application of their prior experiences and beliefs about education when visualizing their ideal classroom. While the above students noted some prior knowledge and beliefs regarding open 
classrooms, zero students surveyed drew any elements of an open classroom. Every picture modeled opportunities for students to work in groups (usually of four desks), but the teacher candidates did not provide opportunities to flexibly work with other classrooms or any other element of an open classroom. So, while they entered the course with appreciation for small group work and student discourse, even those that identified positive feelings about open classrooms did not apply those principles to their ideal classroom.

Whether familiar with the concept or not, a central theme in the journal entries was the unique layout of the school and its open classrooms. Teacher candidates entered the placement with the view that the open classroom layout was a concern or challenge. One teacher candidate noted that "the idea of open classrooms at first threw me off. Especially at younger grades, wouldn't this be a distraction for the students?" Moreover, "this seemed out of the ordinary for me because I've never heard or even been to a school that classrooms were all connected, and just imagined how loud the classroom spaces can get." However, after they spent a couple days in the classroom, they began to see the benefits of the layout.

In addition to the description of the layout, teacher candidates commented on the layout for challenges to instruction. "As soon as I saw that (open classroom), I thought of how the noise level is controlled." Another teacher candidate noted, "At first, I felt as if this could be distracting to the students with the loud noise, but was surprised when I was in the classroom and it didn't seem to be a problem at all." The primary challenge noted by six teacher candidates was the potential for the noise of neighboring classrooms to become a distraction to students and teachers. One reason for these concerns about noise in the classroom was that this layout was counter to their experiences as students and they recognized the potential challenges they might have in this arrangement. "My initial impression of the classroom was that it might be a tough environment to work in because of the open classrooms, but being there with the students was very different from what I thought."

Teacher candidates appreciated the opportunities to more freely communicate with colleagues. After the first week of observation, teacher candidates recognized that students and teachers were accustomed to the layout and classes ran smoothly in regards to the physical space. "What stood out to me was how it all connects, but everyone still has their own space." They described their surprise at the ease in which students and teachers interacted in the open classroom spaces. Additionally, one teacher candidate viewed this as a more "modern" layout due to its focus on community. The open layout allowed for "communication between classroom teachers and specialists [that] is essential." Additionally, "teachers are more available to help one another quicker." Three teacher candidates compared this focus on community to that of a small village focused on the needs of the students.

These sentiments were also echoed as teacher candidates reflected on their experiences in their exit interview. As they considered their professional growth, they recognized that the open classroom layout helped them to value the sense of community that is necessary for their development. They also became more comfortable with observations, since they were always visible to anyone that walked by the classroom. Additionally, one teacher candidate noted that "I am more comfortable in planning my lessons because I have this experience and know that I can go to others for help." While they became more acclimated with the setting and noted its benefits to classroom and school communities, two teacher candidates specifically noted that it would still take some time getting comfortable in that layout. For example, "I think it definitely can help the students and the teachers. But, it still feels very different for me." So, while the experience promoted a sense of community that has benefits for teachers and students, the structure of their schooling as students may continue to drive their views of schools. 


\section{Discussion}

"Teacher educators can support the professional development of pre-service teachers by understanding their concerns and addressing them" (Cevher-Kalburan, 2014, p. 1). Teacher candidates' concerns need to be identified and supported in order to develop their agency and self-efficacy. Current teacher candidates, as members of Generation $Z$, are a very diverse group with varied experiences and beliefs. These new teachers were tested under policies of No Child Left Behind and taught under policies of Race to the Top. Application of ecological systems theory is critical for understanding the impact of various factors on teacher candidates' interactions and the interconnectedness of physical and virtual spaces. The fear and anxiety that results from mass shootings brings concern of physical safety to the surface. Moreover, concerns and fears for physical safety are coupled with the need for emotional support. Other factors - the ubiquitous influence of social media, schools' focus on curbing bullying contribute to a concern for emotional safety.

While the two cohorts responded with differing initial reactions, a close comparison of their responses indicated a focus on teacher and student safety. Research regarding Generation $Z$ is continuing to emerge and this paper seeks to add to that growing body of research. Therefore, the findings in the study are compared to Iorgulescu's (2016) work in studying Generation $Z$ in the workplace. Iorgulescu noted that social and economic conditions of their youth impact Generation Z's demands and expectations. As a result, “...generation $Z$ has a strong need for security” (p. 51). This supports the present argument that individuals from Generation $Z$ are using their early life experience in an area of uncertainty to seek a sense of security. Specifically, there is a desire for physical and emotional support. Williams and Corvo (2005) contend that teacher candidates initially focus on themselves and grow to focus on students. However, the teacher candidates in this study articulated concerns for themselves and their students. In this sense, teacher educators must recognize the capacity of teacher candidates to view their roles as learners and leaders in the classroom. Furthermore, teacher educators support teacher candidates' initial development as educators while teaching them the skills necessary to serve their students. For example, teacher candidates can be taught to view the classroom's physical space in terms of safety as well as ways to support the social emotional development of their students in that context.

The opportunity for community building (Gislason, 2007) through the use of open classrooms must be viewed in the new context of generational characteristics. This generation of teacher candidates have articulated their desire to work in groups, not in isolation (Iorgulescu, 2016). Moreover, they desire support from superiors, both chronological and hierarchical, to develop their skills and relationships. This desire for collaboration aligns with the original intent of the open classrooms (Drummond, 2017). While the primary focus of this study was the perspectives of teacher candidates, the open classroom model created opportunities for teacher candidates' concerns and desires to more readily surface. As such, further research of this model with these teacher candidates could shed light on a school structure that benefits their needs for support and collaboration. While the creation of more open classroom models is likely cost prohibitive, findings in this study highlight the need for schools to support teachers through more collaborative practices. This is necessary to support initial teachers' development, but also to recognize the characteristics of this new generation of teachers. 


\section{Limitations}

Since the reflective journal entry followed the orientation experience, some teacher candidates may not have initially had concerns until peers raised a particular issue. This may elevate a concern that may have been previously absent or lower in priority. However, teacher candidates' decision to raise this concern in their writing remains an expression of concern.

Since participants were selected through a convenience sample, issues of comparability and translatability (LeCompte \& Preissle, 1993b) are present. To address comparability, the participants and site were described as detailed as possible to allow the reader to compare groups and settings. Methods and procedures were delineated and described to address concerns of transferability.

\section{Conclusion}

Each generation of teachers is a product of the interaction of their environment and social interactions. Therefore, it is necessary for teacher educators to have an understanding of the ways in which these interactions influence the beliefs and values of teacher candidates. One way to develop this understanding is through the use of reflective practices that enable teacher candidates to develop their identity as teachers and consider the juxtaposition of public policy and personal beliefs. While new teachers tend to be concerned with themselves as part of their natural development, the teacher candidates in this study demonstrated a concern for the physical and emotional safety of students. Moreover, the open classroom setting served to highlight teacher candidates' desire for collaboration. As teacher educators, we must recognize this desire and provide opportunities for teacher candidates to learn from one another as well as from mentor teachers.

\section{Declaration of Conflicting Interests}

The author declared no potential conflicts of interest with respect to the research, authorship, and/or publication of this article.

\section{Funding}

The authors received no financial support for this research.

ORCID iD

Adam Huck (iD https://orcid.org/0000-0001-7235-0008

\section{References}

Alpan, B. G., Özer, A., Erdamar, K. G., \& Subaşı, G. (2014). The development of a student teacher concerns scale. Eurasian Journal of Educational Research, 54, 151-170. https://doi.org/10.14689/ejer.2014.54.9

Apple, M. W. (2013). Educating the "right" way: Markets, standards, God, and Inequality (2nd ed.). Routledge.

Bandura, A. (2001). Social cognitive theory: An agentic perspective. Annual Review of Psychology, 52,1-26. https://doi.org/10.1146/annurev.psych.52.1.1 
Bandura, A. (2006). Toward a psychology of human agency. Perspectives on Psychological Science, 1(2), 164-180. https://doi.org/10.1111/j.1745-6916.2006.00011.x

Barrett, S. E. (2013). Becoming an activist science teacher: A longitudinal case study of an induction intervention. Electronic Journal of Science Education, 17(4), 1-20.

Barrett, S. E. (2015). The impact of religious beliefs on professional ethics: A case study of a new teacher. Canadian Journal of Education, 38(3), 1-21.

Bowman, D. H. (2001). School safety lessons learned: Urban districts report progress. Education Week, 20(38), 1, 14-15.

Brand, S., Felner, R., Shim, M., Seitsinger, A., \& Dumas, T. (2003). Middle school improvement and reform: Development and validation of a school-level assessment of climate, cultural pluralism, and school safety. Journal of Educational Psychology, 95(3), 570-588. https://doi.org/10.1037/0022-0663.95.3.570

Bronfenbrenner, U. (1979). The ecology of human development: Experiments by nature and design. Harvard University Press.

Centers for Disease Control and Prevention. (2017). Trends in the prevalence of behaviors that contribute to violence on school property.

https://www.cdc.gov/healthyyouth/data/yrbs/pdf/trends/2017 violence school property tre nd yrbs.pdf

Cevher-Kalburan, N. (2014). Early childhood pre-service teachers' concerns and solutions to overcome them. South African Journal of Education, 34(1), 1-18. https://doi.org/10.15700/201412120923

Chesnut, S. R., \& Cullen, T. A. (2014). Effects of self-efficacy, emotional intelligence, and perceptions of future work environment on preservice teacher commitment. Teacher Educator, 49(2), 116132. https://doi.org/10.1080/08878730.2014.887168

Deed, C., \& Lesko, T. (2015). 'Unwalling' the classroom: Teacher reaction and adaptation. Learning Environments Research, 18(2), 217-231. https://doi.org/10.1007/s10984-015-9181-6

Domović, V. (2011). Učiteljska profesija i profesionalni identitet učitelja [The teaching profession and professional identity of teachers]. In:V. Vizek Vidović (Ed.),Učitelji i njihovi mentori. Institut za društvena istraživanja.

Drummond, S. (2017, March 27). 'Open schools' made noise in the '70s; Now they're just noisy. All things considered. https:/www.npr.org/sections/ed/2017/03/27/520953343/openschools-made-noise-in-the-70s-now-theyre-just-noisy

Erickson, F. (2004). Demystifying data construction and analysis. Anthropology \& Education Quarterly, 35(4), 486-493. https://doi.org/10.1525/aeq.2004.35.4.486

Fajet, W., Bello, M., Leftwich, S. A., Mesler, J. L., \& Shaver, A. N. (2005). Pre-service teachers' perceptions in beginning education classes. Teaching and Teacher Education, 21(6), 717-727. https://doi.org/10.1016/i.tate.2005.05.002

Federal Commission on School Safety. (2018). Final Report. https://www2.ed.gov/documents/school-safety/school-safety-report.pdf

Garza, R., Werner, P., \& Wendler, L. F. (2016). Transitioning from student to professional: Preservice teachers' perceptions. New Waves - Educational Research \& Development, 19(2), 19-35.

Gislason, N. (2007). Placing education: The school as architectural space. Paideusis, 16(3), 5-14.

Glesne, C. (2011). Becoming qualitative researchers (4th ed.). Pearson.

Haddix, M. (2015). Preparing community-engaged teachers. Theory Into Practice: Critical ServiceLearning Initiatives, 54(1), 63-70. https://doi.org/10.1080/00405841.2015.977664 
Hayes, N. (1997). Theory-led thematic analysis: Social identification in small companies. In N. Hayes (Ed.), Doing qualitative analysis in psychology (pp. 93-114). Psychology Press.

Ingman, B. C. \& McConnell Moroye, C. (2019). Experience-based objectives. Educational Studies, 55(3), 346-367. https://doi.org/10.1080/00131946.2018.1544900

Iorgulescu, M.-C. (2016). Generation $\mathrm{Z}$ and its perception of work. Cross-Cultural Management Journal, 18(1), 47-54.

Johnson, S. M., \& Birkeland, S. E. (2003). Pursuing a "sense of success": New teachers explain their career decisions. American Educational Research Journal, 40(3), 581-617. https://doi.org/10.3102/00028312040003581

LeCompte, M. D., \& Preissle, J. (1993a). Analysis and interpretation of qualitative data. In Ethnography and qualitative design in educational research(2nd ed., pp. 234-278). Academic.

LeCompte, M. D., \& Preissle, J. (1993b). Considerations on selecting a research design. In Ethnography and qualitative design in educational research (2nd ed., pp. 30-55). Academic.

Luft, J. A. (2009). Beginning secondary Science teachers in different induction programmes: The first year of teaching. International Journal of Science Education, 31(17), 2355-2384. https://doi.org10.1080/09500690802369367

Miksza, P., \& Berg, M. (2013). A longitudinal study of preservice music teacher development: Application and advancement of the Fuller and Bown teacher-concerns model. Journal of Research in Music Education, 61(1), 44-62. https://doi.org/10.1177/0022429412473606

Miller, S.J. (2007). The loaded matrix in classroom and school environments. Counterpoints, 311, 3383. www.jstor.org/stable/42979726

Morse, J. M. (2015). Critical analysis of strategies for determining rigor in qualitative inquiry. Qualitative Health Research, 25(9), 1212-1222. https://doi.org/10.1177/1049732315588501

National Center for Education Statistics. (2018, March). Safety and security measures taken by public schools. https://nces.ed.gov/programs/crimeindicators/ind 20.asp

Neal, J., \& Neal, Z. (2013). Nested or networked? Future directions for ecological systems theory. Social Development, 22(4), 722-737. https://doi.org/10.1111/sode.12018

Oruç, N. (2013). Early teacher identity development. Procedia - Social and Behavioral Sciences, 70 , 207-212. https://doi.org/10.1016/j.sbspro.2013.01.056

Pace, J. L. (2011). The complex and unequal impact of high stakes accountability on untested social studies. Theory \& Research in Social Education, 39(1), 32-60. https://doi.org/10.1080/00933104.2011.10473446

Phi Delta Kappa International. (2018). The 50th annual PDK Poll of the Public's Attitudes Toward the Public Schools: Teaching: Great respect, dwindling appeal. https://www.kappanonline.org/wp-content/uploads/2018/08/PDK-Poll-2018.pdf https://doi.org/10.1177/0031721718797117

Redding, C. \& Henry, G. T. (2019). Leaving school early: An examination of novice teachers' withinand end-of-year turnover. American Educational Research Journal, 56(1), 204-236. https://doi.org/10.3102/0002831218790542

Rose, C. A., Monda-Amaya, L. E., \& Preast, J. L. (2018). Pre-service special and general educators' perceptions of bullying. Exceptionality Education International, 28(2), 33-54.

Schwartz, K. (2014). How opening up classroom doors can push education forward. https://www.kqed.org/mindshift/33897/how-opening-up-classroom-doors-can-pusheducation-forward 
Schroeder, S. (2016). Surveillance, violence, and the marginalization of students of color. Perspectives on Urban Education, 13(1), 56-59.

Seemiller, C., \& Grace, M. (2016). Beliefs and perspectives. In Generation Z goes to college. JosseyBass.

Sexton, D. M. (2008). Student teachers negotiating identity, role, and agency. Teacher Education Quarterly, 35(3), 73-88.

Šimić Šašić, S., Šimunić, A., Ivković, A. \& Ključe, A. (2018). The correlation of perceptions of professional roles and teacher beliefs with the quality of teacher interaction. Journal of Research in Science, Mathematics and Technology Education, 1(2), 207-227. https://doi.org/10.31756/jrsmte.125

Smith, S. M. (2011). Creating safe learning environments for at-risk students in urban schools. The Clearing House, 84, 123-126. https://doi.org/10.1080/00098655.2011.564970

White, B. L., \& Beal, G. D. (1999). Violence in schools as perceived by preservice and in-service teachers. Contemporary Education, 71(1), 31-40.

Williams, K., \& Corvo, K. (2005). "That I'll be killed": Pre-service and in-service teachers' greatest fears and beliefs about school violence. Journal of School Violence, 4(1), 47-69. https://doi.org/10.1300/J202v04n01 04 
Name

\section{Appendix A}

Major

1. Current strengths related to literacy instruction:

2. Areas you hope to improve with the help of this course

3. Elementary School Type (Rural, Suburban, Urban)

4. Elementary school safety drills participated in:

5. Secondary School(s) Type (Rural, Suburban, Urban)

6. Secondary school safety drills participated in:

7. Have you taken a classroom management course? Which one(s)?

8. What do you currently know or believe about open classrooms?

9. What is the kindest message you have received from a teacher/professor?

10. Many factors must be taken into consideration when designing the layout of a classroom. On the back of this paper, sketch a realistic, ideal classroom. 


\section{Appendix B \\ Exit Interview}

At the conclusion of the semester, you will meet individually for 20 minutes with the course instructor to reflect on your work and experiences in the course. The following questions will be used to guide the interview:

Review of:

- Portfolios

- Self-evaluation

What have you learned about literacy that you will take into your future teaching?

In what ways have you changed as a teacher since the beginning of this semester? (What have you learned? What new skills do you have? With what are you more comfortable?)

What are your personal and professional goals for your next teaching experience? (On what specific areas do you plan to focus during your next field placement?)

What ideas do you have to improve the course and/or field placement?

What advice would you give future teacher candidates about the course?

Final thoughts/comments? 


\section{Appendix C}

Reflective Journals Rubric

\begin{tabular}{|l|l|l|l|}
\hline & $\begin{array}{l}\text { Unacceptable (0 } \\
\text { points) }\end{array}$ & Acceptable (1 point) & Target (2 points) \\
\hline Description & $\begin{array}{l}\text { Many aspects of the } \\
\text { prompt are missing }\end{array}$ & $\begin{array}{l}\text { Response addresses } \\
\text { some aspects of the } \\
\text { prompt }\end{array}$ & $\begin{array}{l}\text { Completely and } \\
\text { thoroughly respond to } \\
\text { all aspects of prompt }\end{array}$ \\
\hline Supporting Examples & $\begin{array}{l}\text { Few, if any, examples } \\
\text { are used to support } \\
\text { claim statements }\end{array}$ & $\begin{array}{l}\text { Some examples are } \\
\text { used to support claim } \\
\text { statements }\end{array}$ & $\begin{array}{l}\text { Multiple examples are } \\
\text { used to support claim } \\
\text { statements }\end{array}$ \\
\hline $\begin{array}{l}\text { Connection to } \\
\text { Readings }\end{array}$ & $\begin{array}{l}\text { No connection to } \\
\text { course readings }\end{array}$ & $\begin{array}{l}\text { Vaguely connects } \\
\text { reflection to topics } \\
\text { from course readings }\end{array}$ & $\begin{array}{l}\text { Response clearly } \\
\text { connects to topics and } \\
\text { strategies from course } \\
\text { readings }\end{array}$ \\
\hline $\begin{array}{l}\text { Practice } \\
\text { Connect Theory to }\end{array}$ & $\begin{array}{l}\text { No connection to } \\
\text { educational theory }\end{array}$ & $\begin{array}{l}\text { Vaguely connects } \\
\text { reflection to } \\
\text { educational theories }\end{array}$ & $\begin{array}{l}\text { Response clearly } \\
\text { connects educational } \\
\text { theory to reflection } \\
\text { with elaboration }\end{array}$ \\
\hline Conventions & $\begin{array}{l}\text { Numerous errors in } \\
\text { spelling, punctuation, } \\
\text { capitalization, grammar } \\
\text { \&/or usage }\end{array}$ & $\begin{array}{l}\text { Minor errors in } \\
\text { spelling, punctuation, } \\
\text { capitalization, } \\
\text { grammar, \&/or usage. }\end{array}$ & $\begin{array}{l}\text { Minimal errors in } \\
\text { spelling, punctuation, } \\
\text { capitalization, grammar } \\
\text { \&/or usage. Excellent } \\
\text { demonstration of } \\
\text { standard writing } \\
\text { conventions that } \\
\text { enhances readability }\end{array}$ \\
\hline
\end{tabular}

